\title{
LA RECEPCIÓN Y JERARQUÍA DE LOS TRATADOS EN EL DERECHO INTERNO DE LOS ESTADOS AMERICANOS
}

\author{
THE RECEPTION AND HIERARCHY OF TREATIES IN THE INTERNAL LAW \\ OF AMERICAN STATES
}

\author{
Jorge Luis Silva González, Yesenia Tamayo Zamora y \\ Amarys Morejón Madiedo *
}

\section{RESUMEN}

En el presente estudio se argumentan los retos de la región americana en materia de recepción y jerarquía normativa de los tratados en el Derecho Interno de los Estados. Para ello, con el empleo del método análisis jurídico-doctrinal, se sistematizan los referentes teóricos jurídicos sobre los tratados y su relación con el Derecho Interno. Asimismo, se analiza el estado actual de la recepción y jerarquía normativa de los tratados en las constituciones de 21 Estados americanos.

Palabras clave: Derecho Internacional Público, Derecho Interno, Estado, tratados, recepción, jerarquía, América, Constitución, retos.

\begin{abstract}
ABASTRACT
In this study the challenges of the American region in terms of reception and regulatory hierarchy of international treaties in the Internal Law of States are argued. To do this, using the legal-doctrinal analysis method, the theoretical references on treaties and their relationship with Internal Law are systematized. Likewise, the current status of the reception and regulatory hierarchy of treaties in the constitutions of 21 American States is analyzed.
\end{abstract}

\footnotetext{
* Jorge Luis Silva González.

Licenciado en Derecho y Máster en Desarrollo Social. Profesor principal de Derecho Internacional Público de la Universidad de Pinar del Río, Cuba. Presidente del Capítulo Científico de Derecho Internacional de la Unión Nacional de Juristas filial-Pinar del Río. ORCID: 0000-0002-0214-9744. Email: silva@upr.edu.cu
}

Yesenia Tamayo Zamora

Estudiante de 4to año de Licenciatura en Derecho de la Universidad de Pinar del Río. Secretaria Ejecutiva en el Tribunal Provincial Popular de Pinar del Río. E-mail: yesenia.tamayo@estudiantes.upr.edu.cu

\section{Amarys Morejón Madiedo}

Estudiante de 4to año de Licenciatura en Derecho de la Universidad de Pinar del Río. Asistente Judicial del Tribunal Municipal Popular de Pinar del Río. E-mail: amarys.morejon@estudiantes.upr.edu.cu 
Keywords: Public International Law, Internal Law, State, treaties, reception, hierarchy, America, Constitution, challenges.

\section{Introducción}

"Los tratados internacionales no pueden desplegar su propia eficacia en el Derecho interno sin que este lo consienta aunque sea implicitamente".

Antonio LA PÉRGOLA (1977)

El Derecho Internacional Público es una rama del Derecho de origen consuetudinario, puesto que en sus inicios era la costumbre internacional la fuente primordial de la cual emanaban la mayoría de las normas universales que conformaban su contenido. Sin embargo, este es un derecho provisto de un carácter dinámico y mutable, como resultado de la evolución social, política y económica que experimenta permanentemente la comunidad internacional (HERNÁNDEZ, 2004).

Ha sido precisamente el carácter dinámico y progresista el que ha permitido que los tratados representen hoy la fuente directa principal de dicha rama, ante la carencia de un órgano legislativo y un poder centralizado. Dentro de sus objetivos esenciales está el de constituir un mecanismo para regular las relaciones multifacéticas entre los Estados, y entre estos y las Organizaciones Internacionales, para garantizar la paz y la supervivencia de la sociedad internacional.

De hecho, tal ha sido su importancia -que desde el punto de vista teórico- disímiles autores a escala global y del ámbito nacional cubano han dirigido sus investigaciones hacia su conceptualización, tratamiento jurídico y trascendencia sociojurídica nacional e internacional. Entre ellos se encuentran: Julio D. GonZÁlez CAMPOS, Luis I. SÁNCHEZ Rodríguez, y M. Paz Andrés SÁenz De Santa María (1990), José A. Pastor RIDRUEJO (1992), Natalio CHEDIAK, (1936; 1937), Miguel Antonio D’EstéFANo PISANI (1965; 1977), Manuel Diez de Velasco (1991), Juan Antonio Carrillo Salcedo, (1994),Cesário GutiérRez EsPAdA (1995), G. Tunkin (1998), Manuel BECERRA Ramírez (2000; 2006), Celeste Elena Pino CANALES (2006), Olga Miranda Bravo (2006), Humberto HeNDERSON (2010), y Crisólogo Bustos VALDERRAMA (2010).

Existe consenso desde el punto de vista doctrinal en que un tratado es "un acuerdo de voluntades entre sujetos de derecho internacional, destinados a crear, modificar o extinguir obligaciones internacionales" (BARBOSA, 1996, p.107). La Convención de Viena sobre el Derecho de los Tratados de 1969 establece en su artículo 2.1.a) que un tratado es "un acuerdo internacional concluido por escrito entre Estados y regido por el derecho internacional, sea consignado en un instrumento único o en dos o más instrumentos conexos y sea cual fuere su denominación particular" (NACIONES UNIDAS, 2020).

Considerando actualmente a los tratados la fuente principal del Derecho Internacional, debe analizarse la relación que estos tienen con el Derecho Interno de los Estados, entendiéndose a este último, como el conjunto de normas que regulan y organizan las relaciones jurídicas internas que se desarrollan dentro de las fronteras del Estado. Esta cuestión, representa uno de los temas más controvertidos en el ámbito de la dogmática internacional. 
La significación del tema ha sido destacada por PASTOR RIDRUEJO (1992), cuando señala que la importancia de las relaciones entre el Derecho Internacional y el Derecho Interno, radica en el hecho de que la eficacia real del primero depende en muy amplia medida de la fidelidad con que los derechos internos se conformen a las normas internacionales y les den efecto. Considera esencial que el derecho nacional facilite el cumplimiento del Derecho Internacional y más aún que, en caso de conflicto, el derecho del Estado no sea obstáculo para la observancia de las normas internacionales.

El resultado práctico de esta relación resulta evidente en los casos en los cuales el Estado ratifica un tratado, que requiere de una norma interna para su realización, o en aquellas situaciones en las que, como resultado del acuerdo, se hace necesaria la modificación de normas internas vigentes, por resultar contrarias al mismo. La magnitud de dicha relación también ha sido centro de análisis para autores como Oscar RABASA (1993), Antonio LA PÉRgOla, (1997), Claudio LuZZATi (1999), Olga SÁnCHEZ Cordero de García de Villegas (1999), Elma del Carmen Trejo García, Alma ARÁMbUla REYes y Margarita Álvarez Romero (2006), Boris MIRKINEGueTZEVITCH (2008), Roberto Molina PASQuel (2010), Alberto Luis ZuPPI (2010), y Orisell RichARDS MARTínEZ (2011), Federico THOMAS (2012).

Los Estados americanos no escapan de la necesidad de tener bien delimitada la relación existente entre los tratados y su Derecho Interno, a pesar de que constituyen una comunidad bastante homogénea como parte integrante de la sociedad universal, por el carácter de sus instituciones jurídico-políticas. En ese sentido, se hace ineludible analizar la incorporación de los tratados en el Derecho Interno de los Estados americanos y, la jerarquía de los tratados en ese propio Derecho Interno, a fin de evitar conflictos que puedan surgir como consecuencia de colisionar el contenido de los tratados con las normas de Derecho Interno de los Estados.

Es preciso señalar que, actualmente, no existe unanimidad en los Estados americanos sobre el establecimiento de un sistema para la recepción de los tratados, ni acuerdo respecto al rango que emplean para determinar la jerarquía de los mismos. Razón por la cual el presente estudio tiene como objetivo argumentar los retos de la región americana en materia de recepción y jerarquía normativa de los tratados en el Derecho Interno de los Estados.

Para ello, se empleó como método el análisis jurídico-doctrinal fundamentado por PÉREZ HERNÁNDEZ (2011). El mismo posibilitó la realización del marco teóricoconceptual del estudio y sobre todo, la argumentación de los retos a partir de la valoración del estado actual de los tratados en materia de recepción y jerarquía normativa en el Derecho Interno, por medio de la Constitución de los siguientes Estados: República de Cuba, Estados Unidos de América, Estado Plurinacional de Bolivia, Estados Unidos Mexicanos, República de Ecuador, República Bolivariana de Venezuela, República del Perú, Chile, República Federativa de Brasil, Honduras, Colombia, República de Nicaragua, República de Panamá, República de Costa Rica, República de Haití, República de Paraguay, Argentina, República de El Salvador, República de Guatemala, República Oriental de Uruguay y República Dominicana.

Se considera que el presente artículo es pertinente y novedoso, teniendo en cuenta que podría aportar un análisis vital en los estudios de Derecho Internacional Público sobre las relaciones internacionales, dada la necesidad de continuar el estudio de la correlación entre el Derecho Interno y el Derecho Internacional, partiendo de que los tratados o convenios internacionales constituyen la primera y más importante de las 
fuentes del Derecho Internacional. Serviría de referente teórico importante desde el derecho comparado y, de manera específica en el continente americano. Y posibilitaría comprender el valor que reciben los tratados en el ordenamiento jurídico interno de la región.

\section{Referentes teóricos jurídicos sobre los tratados: su relación con el Derecho Interno de los Estados}

Los tratados constituyen una de las instituciones más antiguas en la historia de la humanidad, pues su presencia es anterior, inclusive, a la existencia del Derecho Internacional Público, como uno de los factores característicos de la etapa esclavista en la historia de esta rama del Derecho (D’EsTÉFANO, 1977). Dichos tratados pueden crear normas de carácter general, cuando las partes expresan su voluntad en pie de igualdad, sin que medie la amenaza o el uso de la fuerza, y de conformidad con los principios del Derecho Internacional universalmente reconocidos, pues constituyen acuerdos de voluntades a cuyo tenor la norma pacta sunt servanda atribuye un efecto vinculante para las partes.

Diversos autores han ofrecido definiciones sobre lo que debería entenderse por tratado. Para Antonio Linares, "es un instrumento donde se consignan disposiciones libremente pactadas entre dos o más sujetos de Derecho Internacional con el fin de crear, modificar o extinguir obligaciones y derechos" (LINARES, 1992, p. 61).

En tanto, para MIRANDA (2006):

Tratado es un término genérico que abarca todos los instrumentos vinculantes con arreglo al Derecho Internacional, cualquiera que sea su designación formal, concertados entre dos o más personas jurídicas internacionales. Por ello tenemos tratados concertados entre Estados, o entre Organizaciones internacionales con capacidad para celebrar tratados y Estados, u Organizaciones Internacionales con capacidad para celebrar tratados entre sí (p. 80).

De esta última definición de la investigadora cubana Olga MIRANDA BRAVo se pueden destacar los siguientes elementos como esenciales:

...Es un instrumento: Se ha sostenido que todo tratado internacional debe constar en un documento escrito, debido a que la posición mayoritariamente acogida en la esfera internacional ha sido aceptar que un consenso puramente verbal no tendría el carácter vinculante $\mathrm{u}$ obligatorio para los miembros de la comunidad internacional participantes del mismo; sin embargo, se considera que en caso de existir tratados puramente verbales deben ser respetados y aceptados por las partes del mismo, de conformidad con la regla pacta sunt servanda, consagrada en el artículo 26 de la Convención de Viena de 1969 sobre el Derecho de los Tratados, que se traduce en el cumplimiento de buena fe de las obligaciones internacionales asumidas por un sujeto de derecho internacional.

Dicha Convención de Viena plantea en su artículo 3 que, aunque ese instrumento legal no se aplique a los acuerdos internacionales no celebrados por escrito, estos no carecen, por esa razón, de valor jurídico. Señala GUTIÉRREZ (1995) que en todo caso se rigen por las normas del derecho internacional consuetudinario.

...Entre dos o más sujetos de Derecho Internacional: Se considera que en todo tratado (respetando las diversas opiniones) deben formar parte al menos dos sujetos de Derecho 
Internacional Público, ya sean Estados u Organizaciones Internacionales, puesto que se habla de un acuerdo de voluntades pactado entre ellos, lo que implica la existencia mínima de dos sujetos, ya que de lo contrario no pudiera suscitarse el desacuerdo o diferencia a regular mediante este instrumento.

...con el fin de crear, modificar o extinguir obligaciones y derechos: Todo tratado se realiza con la finalidad de regular determinada situación, ya sea mediante la creación de disposiciones (si no existen), la modificación de las mismas (en el caso de que existan y ameriten algún cambio) o extinguirlas cuando se consideren innecesarias o haya imposibilidad de cumplimiento por parte de los estados miembros. Es un principio aceptado que de todo tratado emergen derechos y obligaciones (normas jurídicas internacionales), que son de obligatorio cumplimiento para los signatarios de dicho instrumento internacional.

Otra definición interesante es la expuesta por Charles Rousseau, quien señala que un tratado "es un acuerdo entre sujetos del Derecho de Gentes destinado a producir determinados efectos jurídicos" (ROUSSEAU, 1982, p. 23). Mientras que GuTIÉRREZ (1995) lo define como "la manifestación concordante de voluntades, imputable a dos o más sujetos de Derecho Internacional, destinada a producir efectos jurídicos entre las partes, y regida por el ordenamiento jurídico internacional" (p. 259).

A los efectos del presente artículo se coincide con la definición establecida en la Convención de Viena de 1969, artículo 2.1.a) que plantea:

Se entiende por 'tratado' un acuerdo internacional celebrado por escrito entre Estados y regido por el Derecho Internacional y regido por el Derecho Internacional, ya conste en un documento único o en dos o más instrumentos conexos y cualquiera que sea su denominación particular (NACIONES UNIDAS, 2020). Por medio del tratado las partes se proponen crear derechos y obligaciones exigibles de conformidad con el derecho internacional. No existe ninguna norma internacional de cuándo debe utilizarse el término "tratado" de forma específica, pero generalmente se utiliza para instrumentos de cierta importancia y solemnidad. Sin embargo, la denominación de tratados comprende a este y a otras nomenclaturas como convención, convenio, acuerdo, protocolo, pacto, estatuto, acta (MIRANDA, 2006).

Según PINO (2006), debido a la ausencia de regulación en el siglo XIX, se utilizaba el término "convención" para los acuerdos bilaterales pero ahora se utilizan generalmente para los multilaterales. Las convenciones están abiertas a la participación de la comunidad internacional en su conjunto o a la de un gran número de Estados. Los instrumentos negociados con los auspicios de una organización internacional se titulan normalmente convenciones así como los aprobados por un órgano de una organización internacional.

"Convenio" se utiliza para los de rango inmediato y más bien se emplea para los tratados bilaterales y determina relaciones en una temática específica, como por ejemplo, Convenio Cultural, Convenio de Asistencia Técnica, Convenio Comercial. Acuerdo se emplea en temáticas muy variadas y para darle un rango inferior al de Convenio o Convención y a veces derivado de estos. "Estatutos" se aplica a documentos más bien de carácter constitutivos. "Pacto", se emplea con frecuencia en relaciones políticas y militares, como Pacto de No Agresión, por ejemplo.

"Protocolo" se ha dado en llamar a acuerdos internacionales bien modificativos o complementarios de otros tratados principales o derivados de ellos y, por su parte, acta, 
es un término que se ha empleado con frecuencia para recoger acuerdos finales de una Conferencia y se trata de un documento formal mediante la cual las partes negociadoras dan fin a una conferencia. No hay obligación de firmarla y no crea obligaciones jurídicas ni obliga a los Estados signatarios a firmar o ratificar un tratado adjunto a ella. Solo sirve para dejar constancia de lo que allí se trató, pero sin carácter vinculante.

Un tratado es bilateral, cuando es entre dos partes y multilateral cuando es entre más de dos partes. Los Estados manifiestan su voluntad en cumplir un tratado, según el artículo 11 y siguientes de la Convención de Viena de 1969, mediante la firma, el canje de instrumentos que constituyan el tratado, la ratificación, la aceptación, la aprobación o la adhesión o cualquiera otra forma que se hubiere convenido (NACIONES UNIDAS, 2020).

Los tratados son objeto de una doble regulación jurídica, puesto que debe existir, por un lado, una normativa a nivel internacional, y por el otro, las normas internas de los sujetos del Derecho Internacional partes de los mismos, debido a que cada uno de estos sujetos, conforme a su ordenamiento jurídico interno, diseña un procedimiento propio para la celebración, negociación, aprobación, ratificación de estos instrumentos de gran trascendencia internacional.

Esta colisión que puede surgir entre Derecho Interno e Internacional, produce al decir de Diez de Velasco, una dicotomía, por lo que resulta necesario saber si entre el uno y el otro existen o no relación y si se da o no una subordinación entre ellos y asimismo si la norma internacional se incorpora o no automáticamente al Derecho Interno de los Estados (DIEZ DE VELASCO, 2003, p.211).

Para una mejor compresión de la relación entre Derecho Interno y Derecho Internacional, existen distintas posiciones doctrinales que tratan de dar respuesta a esta cuestión. Según PINO (2006) "estas corrientes doctrinales se expresan en tres posiciones: el monismo, el dualismo y la doctrina seguida por los países del antiguo campo socialista” (p. 48).

Una de las principales problemáticas que se afrontan prima facie cuando se pretenden hacer algunas reflexiones en torno a las relaciones entre el Derecho Interno y el Derecho Internacional es lo que se refiere a la delimitación conceptual y, consecuentemente, el alcance de la recepción del Derecho Internacional en el ordenamiento jurídico interno (RICHARDS, 2011).

La aproximación a la delimitación conceptual de la recepción de los tratados, como parte de los vínculos establecidos entre el orden nacional e internacional, se encuentra directamente relacionado a las posiciones doctrinales que interpretan las relaciones entre ambos sistemas. Constituye un procedimiento a través del cual se incorpora la preceptiva internacional al ordenamiento jurídico interno, desde las exigencias nacionales y, en pos de garantizar su debida aplicación a partir de la correspondencia que debe caracterizar las relaciones entre ambos ordenamientos jurídicos (RICHARDS, 2011).

La relación entre Derecho Interno y Derecho Internacional se manifiesta de manera particular en el tema de cómo los Estados recepcionan en su Derecho Interno, los tratados de los cuales son parte, pues para el cabal cumplimiento del Derecho Internacional no basta que los Estados se comprometan formalmente a cumplir determinada norma internacional, resulta necesario, que a la vez establezcan las medidas legislativas internas con vistas a realizar de forma práctica el postulado internacional (PINO, 2006). 
La aplicación delos tratados no se realiza de manera homóloga en todos los Estados. Es posible distinguir varios sistemas para la recepción de estos, a saber: sistema de la recepción automática, sistema de recepción formal o especial y carencia de regulación expresa (PINO, 2006).

Para dicha autora, el sistema de la recepción automática implica la aplicación del tratado, una vez que el Estado haya manifestado su consentimiento y el tratado entrara en vigor, sin que resulte necesario ningún acto posterior de conversión en norma interna. Es un sistema en el cual, la aplicación del tratado, por parte de las autoridades del Estado, resulta obligatoria de manera automática, una vez que el Estado en cuestión haya manifestado su consentimiento y el tratado entrare en vigor, sin que sea necesario ningún acto de incorporación al Derecho Interno. Es necesario aclarar que no se debe entender como actos de incorporación, los mecanismos administrativos establecidos, para el conocimiento de la norma, o la intervención previa del legislativo para su aprobación interna.

En el sistema de recepción formal o especial, la normativa interna del Estado exige que la incorporación se produzca a través de una ley interna de transformación, mediante la aprobación por el legislativo de una norma que ordene su cumplimiento en el Derecho Interno o mediante la publicación del tratado como acto equivalente a su promulgación. En este caso la entrada en vigor interna e internacional del tratado se produce en momentos diferentes.

En el caso de la carencia de regulación expresa, la Constitución del Estado resulta omisa al no existir en el texto constitucional regulación tácita sobre la incorporación de los tratados en el Derecho Interno, por lo que para determinar la incorporación de los mismos al Derecho Interno de dicho Estado se atenderá a la práctica administrativa o jurisdiccional para determinar el mecanismo de incorporación.

Independientemente del sistema de incorporación del derecho convencional al Derecho Interno, resulta necesario destacar la existencia de un tipo de normas denominadas autoaplicativas o self-executing, que "son aquellas que permiten por sí solas aplicarse, sin que sea necesario el trámite posterior de incorporación" (PINO, 2006, p. 56).

Para la mencionada autora, la doctrina reconoce que una norma es autoaplicativa cuando cumple los siguientes requisitos: a) Deber ser una norma de la cual sea posible derivar en forma directa un derecho o una pretensión a favor de una persona que tenga interés legítimo en la aplicación de la regla en su caso; b) La regla debe ser lo suficientemente específica como para poder ser aplicada judicialmente, sin que su ejecución esté subordinada a un acto legislativo o a medidas administrativas subsiguientes. Según THOMAS (2012):

El primer antecedente de la doctrina judicial de las normas self-executing o autoejecutables lo encontramos en la célebre sentencia del juez Marshall, interpretando la Constitución de 1828 de Estados Unidos, cuando dijo que "los jueces deben considerar a un tratado como equivalente a un acto legislativo, siempre que opere por sí mismo sin ayuda de una disposición legislativa (p. 187)

Paralelamente a los sistemas para la aplicación de los tratados a través de su correspondiente incorporación al Derecho Interno de los Estados, resulta necesario determinar el rango que ocupan en el Derecho Interno de cada Estado. Aquí también 
resultan claramente identificables varias posiciones. Según PINO (2006) pueden ser de rango supraconstitucional, rango supralegal, rango legal y ausencia de regulación.

El rango supraconstitucional ofrece a los tratados una jerarquía superior a la constitución, de ahí que sea el menos utilizado en la doctrina y en la práctica de los Estados. Las razones que motivan esta posición estriban en el valor que tienen las constituciones para los Estados, al ser la norma fundamental que rige la organización, estructura y funcionamiento del Estado, por encima de la cual no se alza ninguna otra disposición de carácter interno o internacional.

Por medio del rango supralegal, las constituciones le reconocen a los tratados un valor inferior a la constitución, pero superior al resto de las leyes nacionales, por lo que priman sobre estas. Este sistema si bien garantiza, en cada país, el rango supremo de la constitución no brinda seguridad jurídica, pues en muchos casos la constitución no regula que sucede con la ley interna posterior y opuesta al tratado.

"La posición del rango legal es la seguida por la mayoría de los países, sobre todo, en América Latina" (PINO, 2006, p. 57). En este sistema a los tratados se les otorga rango de ley, por lo tanto, no pueden contravenir lo estipulado en la constitución. Paralelamente esta equiparación nos plantea el problema que puede surgir por la aprobación posterior, que por sus disposiciones sea contraria al tratado o lo derogue. La solución a esta problemática estará también en estrecha relación con el sistema consagrado en cada país. Sin embargo en caso de que la norma tenga las características antes expuestas, cabría la posibilidad de exigir responsabilidad internacional al Estado infractor.

En el sistema de ausencia de regulación el valor concedido por el Estado, al tratado, no aparece expresamente establecido, o no resulta claro. Por lo tanto carecen de una regulación específica en torno al valor que se le otorga internamente a los tratados.

Las constituciones de los Estados americanos, reflejan la inexistencia de consenso en cuanto a la posición seguida para la recepción y jerarquía de los tratados en su Derecho Interno, lo cual representa un reto en el escenario internacional.

\section{Los tratados en las constituciones de la región americana. Retos para su recepción y jerarquía en el Derecho Interno de los Estados}

Los tratados, además de un régimen internacional común a las partes signatarias entre sí, también necesitan de normas internas establecidas por cada Estado en su propio ordenamiento jurídico. Es a los Estados y a las Organizaciones Internacionales a quienes corresponde precisar cuáles son los órganos competentes para celebrar, negociar, aprobar y ratificar los tratados, diseñar el procedimiento de conclusión e interpretación de estos conforme al Derecho Interno del Estado y, determinar el orden o jerarquía de aplicación en caso de colisión normativa (HERNÁNDEZ, 2004).

A continuación, se analiza cómo se abordan tanto la jerarquía de los tratados como los sistemas para la incorporación de los mismos al Derecho Interno de los Estados, en 21 textos constitucionales del continente americano. Los mismos fueron seleccionados representativamente de manera que hubiese una muestra de América del Norte, América del Sur, Centroamérica y el Caribe. Para ello se toma como criterio de clasificación en ambos casos, los ofrecidos por PINO (2006), expresados con antelación. 
En cuanto a la jerarquía de los tratados en el ordenamiento interno de los Estados analizados, se constata la ausencia de regulación en las constituciones de: la República de Panamá, la República de Haití, los Estados Unidos Mexicanos, Chile, la República Oriental de Uruguay y la República Federativa de Brasil, pues no dedican un espacio en su articulado a hacer referencia a tan importante tema, poniendo en manos de la práctica administrativa o jurisdiccional la regulación al respecto.

Existe otro conjunto de países en los que sí se ha dispuesto en su texto constitucional la supremacía de una u otras normas, predominando entre ellos los que otorgan a los tratados un rango legal, lo cual los equipara al resto de las disposiciones internas del Estado y, por ende, los mismos no pueden contravenir lo estipulado en la constitución. Este es el caso de República de Cuba, el Estado Plurinacional de Bolivia, República del Perú, Honduras, la República de Nicaragua y Guatemala.

La Carta Magna de la República de Cuba, como la más joven de la región, pues fue promulgada el 10 de abril de 2019, aborda el tema de forma clara al establecer por medio del artículo 8 que: "Lo prescrito en los tratados internacionales, en vigor para la República de Cuba, forman parte o se integran, según corresponda, al ordenamiento jurídico nacional. La Constitución de la República de Cuba prima sobre estos tratados internacionales". Asimismo sucede con el artículo 257de la Constitución del Estado Plurinacional de Bolivia en el apartado I, en el cual se dispone: "Los tratados internacionales ratificados forman parte del ordenamiento jurídico interno con rango de ley".

La Constitución del Estado Plurinacional de Bolivia, no solo se pronuncia, en materia de jerarquía de tratados en el citado artículo 257, sino que también establece una regulación expresa al respecto en los artículos 13 apartado IV; 410 apartado II, y en laDisposición Transitoria Novena. El citado texto constitucional regula en el apartado IV del artículo13 que: "Los tratados y convenios internacionales ratificados por la Asamblea Legislativa Plurinacional, que reconocen los derechos humanos y que prohíben su limitación en los Estados de Excepción prevalecen en el orden interno. Los derechos y deberes consagrados en esta Constitución se interpretarán de conformidad con los Tratados internacionales de derechos humanos ratificados por Bolivia". En tanto, en el apartado II del artículo 410 regula lo siguiente: "La Constitución es la norma suprema del ordenamiento jurídico boliviano y goza de primacía frente a cualquier otra disposición normativa. El bloque de constitucionalidad está integrado por los Tratados y Convenios internacionales en materia de Derechos Humanos y las normas de Derecho Comunitario, ratificados por el país. La aplicación de las normas jurídicas se regirá por la siguiente jerarquía, de acuerdo a las competencias de las entidades territoriales:

\section{Constitución Política del Estado.}

2. Los tratados internacionales.

3. Las leyes nacionales, los estatutos autonómicos, las cartas orgánicas y el resto de legislación departamental, municipal e indígena.

4. Los decretos, reglamentos y demás resoluciones emanadas de los órganos ejecutivos correspondientes".

Mientras, en la Disposición Transitoria Novena queda establecido que: "Los tratados internacionales anteriores a la Constitución y que no la contradigan se mantendrán en 
el ordenamiento jurídico interno, con rango de ley. En el plazo de cuatro años desde la elección del nuevo Órgano Ejecutivo, éste denunciará y, en su caso, renegociará los tratados internacionales que sean contrarios a la Constitución".

Similar es el tratamiento que se brinda a los tratados, en materia de jerarquía, en la Constitución de la República del Perú, la cual en el artículo 55 dispone: "Los tratados celebrados por el Estado y en vigor forman parte del derecho nacional”.

En el caso de Honduras, está establecido en el artículo 16 de la Constitución que: "Todos los tratados internacionales deben ser aprobados por el Congreso Nacional antes de su ratificación por el Poder Ejecutivo. Los tratados internacionales celebrados por Honduras con otros Estados, una vez que entran en vigor, forman parte del derecho interno". Por su parte, el texto constitucional de la República de Nicaragua plantea en su artículo 182 que: "La Constitución Política es la carta fundamental de la República; las demás leyes están subordinadas a ella. No tendrán valor alguno las leyes, tratados, órdenes o disposiciones que se le opongan o alteren sus disposiciones". En tanto, la Constitución de Guatemala establece en el artículo 204, relativo a las condiciones esenciales de la administración de justicia, lo siguiente: "Los tribunales de justicia en toda resolución o sentencia observarán obligadamente el principio de que la Constitución de la República prevalece sobre cualquier ley o tratado”.

Otro de los rangos otorgados a los tratados, en las constituciones americanas es el que les reconoce a los mismos un valor inferior a la constitución, pero superior al resto de las leyes nacionales, siendo este el rango supralegal, dentro del que se ubican la República de Ecuador, Colombia, la República de Costa Rica, la República de Paraguay, la República de El Salvador, la República Dominicana, la República Bolivariana de Venezuela y Argentina.

El texto constitucional de la República de Ecuador en su artículo 84 plantea: "La Asamblea Nacional y todo órgano con potestad normativa tendrá la obligación de adecuar, formal y materialmente, las leyes y demás normas jurídicas a los derechos previstos en la Constitución y los tratados internacionales, y los que sean necesarios para garantizar la dignidad del ser humano o de las comunidades, pueblos y nacionalidades. En ningún caso, la reforma de la Constitución, las leyes, otras normas jurídicas ni los actos del poder público atentarán contra los derechos que reconoce la Constitución"; mientras que en el artículo 417 establece: "Los tratados internacionales ratificados por el Ecuador se sujetarán a lo establecido en la Constitución. En el caso de los tratados y otros instrumentos internacionales de derechos humanos se aplicarán los principios pro ser humano, de no restricción de derechos, de aplicabilidad directa y de cláusula abierta establecidos en la Constitución”. En ambos artículos se evidencia que los tratados tendrán un valor inferior a la Constitución, sin embargo, es en el artículo 425 donde se regula que estos tendrán una jerarquía superior al resto de las leyes nacionales, dado que el mismo plantea: "El orden jerárquico de aplicación de las normas será el siguiente: La Constitución; los tratados y convenios internacionales; las leyes orgánicas; las leyes ordinarias; las normas regionales y las ordenanzas distritales; los decretos y reglamentos; las ordenanzas; los acuerdos y las resoluciones; y los demás actos y decisiones de los poderes públicos".

$\mathrm{Al}$ respecto, la Constitución colombiana en el artículo 4 dispone: "La Constitución es norma de normas. En todo caso de incompatibilidad entre la Constitución y la ley u otra norma jurídica, se aplicarán las disposiciones constitucionales"; aludiendo en su artículo 93 que: "Los tratados y convenios internacionales ratificados por el Congreso, 
que reconocen los derechos humanos y que prohíben su limitación en los estados de excepción, prevalecen en el orden interno. Los derechos y deberes consagrados en esta Carta, se interpretarán de conformidad con los tratados internacionales sobre derechos humanos ratificados por Colombia", sin embargo, tal regulación resulta insuficiente, dado que se encuentra limitada exclusivamente a los tratados referidos a los derechos humanos.

Por su parte, el texto constitucional de la República de Costa Rica, en el artículo 7 dispone: "Los tratados públicos, los convenios internacionales y los concordatos debidamente aprobados por la Asamblea Legislativa, tendrán desde su promulgación o desde el día que ellos designen, autoridad superior a las leyes". En tanto, el artículo 137 de la Constitución de la República de Paraguay plantea: "La ley suprema de la República es la Constitución. Esta, los tratados, convenios y acuerdos internacionales aprobados y ratificados, las leyes dictadas por el Congreso y otras disposiciones jurídicas de inferior jerarquía, sancionadas en consecuencia, integran el derecho positivo nacional en el orden de prelación enunciado".

En tanto, la Constitución de la República de El Salvador, en el artículo 144 contempla: "Los tratados internacionales celebrados por El Salvador con otros estados o con organismos internacionales, constituyen leyes de la República al entrar en vigencia, conforme a las disposiciones del mismo tratado y de esta Constitución. La ley no podrá modificar o derogar lo acordado en un tratado vigente para El Salvador. En caso de conflicto entre el tratado y la ley, prevalecerá el tratado”. Mientras el texto constitucional de la República Dominicana, por su parte, en el apartado 3 del artículo 74 refiere: "Los tratados, pactos y convenciones relativos a derechos humanos, suscritos y ratificados por el Estado dominicano, tienen jerarquía constitucional y son de aplicación directa e inmediata por los tribunales y demás órganos del Estado", regulación esta que, tal como sucede en la Constitución colombiana, se limita solamente a aquellos tratados que aluden a los derechos humanos.

A este grupo se les suma la República Bolivariana de Venezuela, dado que en su Carta Magna tampoco se hace alusión a los tratados en general, sino que, se limita a establecer la jerarquía que se le otorga solamente a los tratados relativos a los derechos humanos planteando en el artículo 23 que: "Los tratados, pactos y convenciones relativos a derechos humanos, suscritos y ratificados por Venezuela, tienen jerarquía constitucional y prevalecen en el orden interno, en la medida en que contengan normas sobre su goce y ejercicio más favorables a las establecidas en esta Constitución y en las leyes de la República.

Por su parte, la Constitución de Argentina en el artículo 31 plantea: "Esta Constitución, las leyes de la Nación que en su consecuencia se dicten por el Congreso y los tratados con las potencias extranjeras son la ley suprema de la Nación; y las autoridades de cada provincia están obligadas a conformarse a ella, no obstante cualquiera disposición en contrario que contengan las leyes o Constituciones provinciales, salvo para la Provincia de Buenos Aires, los tratados ratificados después del pacto del 11 de noviembre de 1859"; aludiendo en su artículo 75 que "Los tratados y concordatos tienen jerarquía superior a las leyes", resaltando en el propio artículo que: "La Declaración Americana de los Derechos y Deberes del Hombre; la Declaración Universal de Derechos Humanos; la Convención Americana sobre Derechos Humanos; el Pacto Internacional de Derechos Económicos, Sociales y Culturales; el Pacto Internacional de Derechos Civiles y Políticos y su Protocolo Facultativo; la 
Convención Sobre la Prevención y la Sanción del Delito de Genocidio; la Convención Internacional sobre la Eliminación de Todas las Formas de Discriminación Racial; la Convención Sobre la Eliminación de Todas las Formas de Discriminación Contra la Mujer; la Convención Contra la Tortura y Otros Tratos o Penas Crueles, Inhumanos o Degradantes; la Convención Sobre los Derechos del Niño; en las condiciones de su vigencia, tienen jerarquía constitucional, no derogan artículo alguno de la primera parte de esta Constitución y deben entenderse complementarios de los derechos y garantías por ella reconocidos".

En tal sentido, siendo el menos utilizado, se encuentra el rango supraconstitucional, que otorga a los tratados un valor superior al de la constitución y a los cuales se afilia el texto de los Estados Unidos de América, el cual en su artículo VI dispone: "Esta Constitución y las leyes de los Estados Unidos que deben sancionarse conforme a la misma; y todos los tratados suscritos o que deban suscribirse bajo la autoridad de los Estados Unidos, serán la suprema ley del país; y los jueces en cada Estado se sujetarán a la misma, aún cuando exista algo en contrario en la Constitución o leyes de los Estados".

En cuanto a la recepción de los tratados en el Derecho Interno de los Estados se aprecia una tendencia a la no regulación constitucional debido a que países como Chile, la República de Nicaragua, la República de Panamá, la República de Paraguay, la República de Guatemala y la República Oriental de Uruguay, no abordan el tema.

Existe otro grupo de Estados como la República de Costa Rica, la República de El Salvador y la República Dominicana, que advierten como sistema de recepción, la regulación automática.

Similar es el tratamiento que se hace en la Constitución de la República Bolivariana de Venezuela que contempla en el artículo 23: "Los tratados, pactos y convenciones relativos a derechos humanos, suscritos y ratificados por Venezuela, tienen jerarquía constitucional y prevalecen en el orden interno, en la medida en que contengan normas sobre su goce y ejercicio más favorables a las establecidas en esta Constitución y en las leyes de la República, y son de aplicación inmediata y directa por los tribunales y demás órganos del Poder Público”, aunque la misma resulta restringida debido a que limita su regulación a aquellos tratados que hacen alusión a los derechos humanos; aspecto que también se aprecia en el texto constitucional de la República Dominicana, el cual, como se ha expresado anteriormente, en el apartado 3 de su artículo 74 dispone: "Los tratados, pactos y convenciones relativos a derechos humanos, suscritos y ratificados por el Estado dominicano, tienen jerarquía constitucional y son de aplicación directa e inmediata por los tribunales y demás órganos del Estado”. En el caso de Estados Unidos de América pudiera inferirse por el ya citado artículo VI, que posee también el sistema de recepción automática, aunque no queda claro en el texto constitucional, no se establece taxativamente.

En materia de recepción de tratados, el texto constitucional de la República de Costa Rica, en su artículo 7 contempla: "Los tratados públicos, los convenios internacionales y los concordatos debidamente aprobados por la Asamblea Legislativa, tendrán desde su promulgación o desde el día que ellos designen, autoridad superior a las leyes". En tanto, la Constitución de El Salvador, en su artículo 144 plantea: "Los tratados internacionales celebrados por El Salvador con otros estados o con organismos internacionales, constituyen leyes de la República al entrar en vigencia, conforme a las disposiciones del mismo tratado y de esta Constitución”. 
También existen Estados que dentro de su regulación interna cuentan con normas para la incorporación de los tratados, o, al menos contemplan en su articulado constitucional que existen mecanismos por los cuales la entrada en vigor de los mismos se produce en momentos diferentes. En tal sentido, existe una regulación formal o especial de estos, siendo el caso de países como la República de Cuba, el Estado Plurinacional de Bolivia, República del Perú, Honduras, la República de Haití, los Estados Unidos Mexicanos, Colombia, Argentina, la República Federativa de Brasil y la República de Ecuador.

La Constitución de la República de Cuba otorga a varios órganos de poder estatal la responsabilidad de aprobar, ratificar y sancionar los tratados, ya sean en determinada materia o sobre acuerdos generales. El artículo 108, inciso ñ) plantea que, corresponde a la Asamblea Nacional del Poder Popular declarar el Estado de Guerra o la Guerra en caso de agresión militar y aprobar los tratados de paz; mientras que por el artículo 137 d) establece que el Consejo de Ministros aprueba y somete a la ratificación del Consejo de Estado los tratados internacionales. Finalmente, mediante el artículo 122, inciso ñ) refiere que corresponde al Consejo de Estado ratificar y denunciar tratados internacionales.

La Constitución del Estado Plurinacional de Bolivia, en el apartado I de su artículo 158, específicamente en el numeral 14 alude: "Son atribuciones de la Asamblea Legislativa Plurinacional, además de las que determina esta Constitución y la ley, ratificar los tratados internacionales celebrados por el Ejecutivo, en las formas establecidas por esta Constitución", disponiendo en el apartado II de su artículo 257 que: "Requerirán de aprobación mediante referendo popular vinculante previo a la ratificación los tratados internacionales que impliquen:

\section{Cuestiones limítrofes.}

\section{Integración monetaria.}

\section{Integración económica estructural.}

4. Cesión de competencias institucionales a organismos internacionales o supranacionales, en el marco de procesos de integración”.

En tanto, la Constitución de la República del Perú, en el segundo párrafo del artículo 57 plantea: "Cuando el tratado afecte disposiciones constitucionales debe ser aprobado por el mismo procedimiento que rige la reforma de la Constitución, antes de ser ratificado por el Presidente de la República", mientras la Constitución hondureña, en su citado artículo 16 dispone que: "Todos los tratados internacionales deben ser aprobados por el Congreso Nacional antes de su ratificación por el Poder Ejecutivo". Por su parte, la Constitución haitiana ofrece similar tratamiento en el apartado 2 del artículo 276, el cual plantea que: "Una vez que los tratados o acuerdos internacionales son aprobados y ratificados de la manera estipulada por la Constitución, pasan a formar parte de la legislación del país y derogan cualquier ley en conflicto con ello".

El texto constitucional de los Estados Unidos Mexicanos, en el apartado I del artículo 76, estipula que: "es facultad exclusiva del Senado, aprobar los tratados internacionales y convenciones diplomáticas que celebre el Ejecutivo de la Unión”; aludiendo en el apartado X del artículo 89 que: "es facultad y obligación del presidente, dirigir la política exterior y celebrar tratados internacionales, sometiéndolos a la aprobación del Senado".En tanto, la Constitución colombiana, al final del artículo 170 enuncia: "Un número de ciudadanos equivalente a la décima parte del censo electoral, 
podrá solicitar ante la organización electoral la convocación de un referendo para derogatoria de una ley. No procede el referendo respecto de las leyes aprobatorias de tratados internacionales", contemplando en su artículo 189 apartado 2 que: "Corresponde al Presidente de la República, dirigir las relaciones internacionales. Nombrar a los agentes diplomáticos y consulares, recibir a los agentes respectivos y celebrar con otros Estados y entidades de derecho internacional tratados o convenios que se someterán a la aprobación del Congreso"; disponiendo además, en el artículo 224, referido a las relaciones internacionales lo siguiente: "Los tratados para su validez, deberán ser aprobados por el Congreso. Sin embargo, el Presidente de la República podrá dar aplicación provisional a los tratados de naturaleza económica y comercial acordados en e l ámbito de organismos internacionales, que así lo dispongan. En este caso tan pronto como un tratado entre en vigor provisionalmente, deber enviarse al Congreso para su aprobación. Si el Congreso no lo aprueba, se suspenderá la aplicación del tratado".

Similar tratamiento ofrece la Constitución de Argentina, la cual, en el artículo 75 apartado 22 plantea: "Corresponde al Congreso, aprobar o desechar tratados concluidos con las demás naciones y con las organizaciones internacionales y los concordatos con la Santa Sede", contemplando en el apartado 24 del propio artículo que: "Corresponde al Congreso, aprobar tratados de integración que deleguen competencias y jurisdicción a organizaciones supraestatales en condiciones de reciprocidad e igualdad, y que respeten el orden democrático y los derechos humanos. Las normas dictadas en su consecuencia tienen jerarquía superior a las leyes. La aprobación de estos tratados con Estados de Latinoamérica requerirá la mayoría absoluta de la totalidad de los miembros de cada Cámara. En el caso de tratados con otros Estados, el Congreso de la Nación, con la mayoría absoluta de los miembros presentes de cada Cámara, declarará la conveniencia de la aprobación del tratado y sólo podrá ser aprobado con el voto de la mayoría absoluta de la totalidad de los miembros de cada Cámara, después de ciento veinte días del acto declarativo".

El texto constitucional de la República Federativa de Brasil, se pronuncia respecto al tema en el artículo 49 apartado I, en el cual establece que: "Es de competencia exclusiva del Congreso Nacional, resolver definitivamente sobre tratados, acuerdos o actos internacionales que acarreen encargos o compromisos gravosos para el patrimonio nacional; regulando en el apartado VIII de su artículo 84 que: "Compete privativamente al Presidente de la República, celebrar tratados, convenciones y actos internacionales, sujetos a refrendo del Congreso Nacional".

Por último, la Constitución de la República de Ecuador, en el artículo 120 apartado 8 dispone que: "es atribución de la Asamblea Nacional, aprobar o improbar los tratados internacionales en los casos que corresponda", regulando en el apartado 10 de su artículo 147 que corresponde al Presidente de la República, suscribir y ratificar los tratados internacionales.

Tomando como referencia el análisis realizado en las 21 constituciones del continente americano, se puede afirmar que en la comunidad internacional existen retos respecto a la recepción y jerarquía de los tratados en el Derecho Interno de los Estados. De cumplirse dichos desafíos se garantizaría una mayor validez de los tratados como principal fuente del Derecho Internacional Público, y le darían a esta rama una mayor connotación. Dentro de esos retos podemos mencionar los siguientes: 
Que los Estados establezcan en sus constituciones la forma de recepción que tendrán los tratados en su Derecho Interno.

Ello posibilitaría la previsión del momento a partir del cual el tratado comenzará a ser eficaz en el Estado, de forma automática, o por medio un acto normativo interno, a fin de lograr la debida coherencia y con las disposiciones legislativas vigentes. Debe tenerse en cuenta que el nacimiento del control internacional a tratados, -como figura de verificación del cumplimiento de lo previsto convencionalmente por los mismos- es posterior a su recepción. Seis de las constituciones americanas analizadas resultan omisas al no existir en el texto regulación expresa sobre la incorporación de los tratados en el Derecho Interno.

$\checkmark$ Que los Estados reconozcan en sus constituciones el rango que ocupan los tratados internacionales en el Derecho Interno.

La determinación del rango constitucional de los tratados con relación a la propia Constitución y el resto de las normas del ordenamiento jurídico evitaría colisiones entre las disposiciones internas y las internacionales. Debe asumirse que para el cabal cumplimiento del Derecho Internacional no basta con que los Estados se comprometan formalmente a cumplir determinado acuerdo, sino que, resulta necesario que a la vez establezcan las medidas legislativas internas con vistas a realizar de forma práctica el postulado internacional, toda vez que, la validez real del acuerdo depende en amplia medida de la fidelidad con que el Derecho Interno lo contemple y le dé efecto.

$\checkmark$ Que los Estados, al prever la recepción y jerarquía de los tratados internacionales en su Constitución y por consiguiente, en el Derecho Interno, no la limiten a los derechos humanos.

Como se ha evidenciado en el continente americano constituye una regularidad que los Estados se pronuncian en materia de recepción y jerarquía de los tratados, solamente en correspondencia con los derechos derivados de los derechos humanos, en el orden interno. En tal sentido, aun cuando para los Estados pudiera constituir una prioridad la regulación formal, material y jurisdiccional de los derechos como fundamentales, la celebración de tratados es amplia y no se reduce solo a acuerdos de derechos ciudadanos. Por ello, la Constitución de algunos Estados en la región, debe contemplar una regulación constitucional general que contemple la recepción y jerarquía de todo tipo de tratados en el Derecho Interno.

$\checkmark$ Que la Organización de Naciones Unidas (ONU) promueva un tratado sobre el Sistema de recepción de tratados y su jerarquía en el Derecho Interno de los Estados.

Dada la carencia de un órgano legislativo y un poder centralizado en la comunidad internacional como una de las características fundamentales del Derecho Internacional Público, la creación de un acuerdo internacional a escala global o por regiones sobre el sistema para la recepción y jerarquía de los tratados internacionales en el Derecho Interno de los Estados, sería un paso de avance en el escenario internacional, que posibilitará una mayor garantía de cumplimiento de los acuerdos, basado en el respeto a las particularidades y soberanía de cada Estado en lo referente a sistema económico, político, social. 


\section{Conclusiones}

El análisis valorativo desarrollado en 21 de los Estados de la región americana evidencia que, a pesar de que los tratados constituyen el principal mecanismo para el ejercicio de la relaciones multifacéticas internacionales y la protección de los derechos humanos, existen tres de ellos que no reconocen constitucionalmente la recepción y jerarquía de los tratados. Tal es el caso de la República Oriental de Uruguay, Chile y la República de Panamá.

En materia de recepción de tratados existe diversidad de formas para asumir los acuerdos internacionales en el ordenamiento jurídico interno. Se detecta como regularidad entonces, que seis de los Estados poseen como tendencia la carencia de regulación expresa, cinco países poseen el sistema de recepción automática y diez el de recepción formal o especial. En tanto, la jerarquía normativa de los tratados se comporta de la siguiente forma: seis países posee ausencia de regulación en las constituciones americanas, seis le otorgan rango legal, ocho los ubican con rango supralegal y uno con rango supraconstitucional.

Ante esta situación, los Estados americanos tienen como retos fundamentales: el establecimiento constitucional del sistema de recepción que tendrán los tratados en el Derecho Interno, el reconocimiento constitucional del rango que ocupan los tratados en el ordenamiento jurídico nacional, la previsión de que la recepción y jerarquía de los tratados en su Constitución y por consiguiente, en el Derecho Interno, no se limite a los derechos humanos o fundamentales, y la promoción de un tratado sobre el sistema de recepción de tratados y su jerarquía en el Derecho Interno de los Estados por parte de las Naciones Unidas.

\section{Referencias bibliográficas}

Barbosa, J. (1996). Derecho Internacional Público. Buenos Aires: Zavalia.

BECERRA, M. et al. (2000). Tratados internacionales se ubican jerárquicamente por encima de las leyes y en un segundo plano respecto de la Constitución federal. Cuestiones constitucionales, No 003. Universidad Nacional Autónoma de México. Disponible en http://www.redalyc.uaemex.mx/redalyc/pdf/885/88500307.pdf [citado 2020/01/20]

BeCERRA, M. et al. (2006). La recepción del Derecho internacional en el Derecho interno, $1^{\text {a }}$ Edición, México: Ed. UNAM.

Bustos, C. (2010). Naturaleza jurídica de los tratados y su relación jerárquica con la ley. Revista de Derecho. Disponible en http://www.cde.cl

NaCIONES Unidas (2020). Convención de Viena de 1969. Disponible en https://www.wipo.int/export/sites/www/wipolex/es/glossary/viennaconvention-es.pdf

CARrillo, J. A. (1994).Introducción a su estructura, dinámica y funciones. En Curso de Derecho Internacional Público. Madrid: Ed. TECNOS, S.A. 
Chediak, N. (1936). “El Derecho Internacional y la Constitución Cubana”, Molina y Cía., Muralla 55-57.

Chediak, N. (1937). “Aplicación de las Convenciones Internacionales por el Derecho Nacional", Carasa y Cía., S. Tte. Rey 12 y 14, La Habana.

D’Estéfano, M. A. (1965). Derecho Internacional Público. La Habana: Ed. Universitaria.

D’Estéfano, M. A. (1977). Derecho de Tratados, $2^{a}$ Edición. La Habana: Ed. Pueblo y Educación.

DieZ De Velasco, M. (1991). Instituciones de Derecho Internacional Público, Tomo I, $9^{\text {a }}$ Madrid: Tecnos, S.A.

GonzÁlez, J. D.; SÁnchez, L. I., y SÁEnz, M. P. A. (1990). Curso de Derecho Internacional Público, Volumen I, Servicio de Publicaciones Universidad Complutense de Madrid.

GutiéRrez, C. (1995). Derecho Internacional Público. Madrid: Ed. Trotta.

HENDERSON, H. (2010). Los tratados internacionales de derecho humanos en el orden interno: la importancia del principio pro homine. Disponible en http://www.juridicas.unam.mx/publica/librev/rev/iidh/cont/39/.../pr5.pdf

HERNÁNDEZ, L. L. (2004). Hernández, L. L. (2004). Los tratados internacionales como base de la diplomacia mundial. Revista de Derecho Universidad del Norte Barranquilla No.22, 65-95.

LA PÉRgola, A. (1977). Constitución del Estado y Normas Internacionales, trad. CASCAjo, J. L. y RodríGueZ-ZaPata, J., $1^{\text {a }}$ Edición, México: UNAM.

Linares, J. E. (1992). Derecho internacional Público. Tomo I, Panamá: Ed. Universitaria.

Luzzati, C. (1999). Más allá de Kelsen. Monismo y Pluralismo en el Derecho Internacional. Revista DOXA No. 22_06. Centro de Estudios Constitucionales, Alicante.

Miranda, O. (2006). Derecho de Tratados. En B. Castillo (editora). Colectivo de Autores. Temas de Derecho Internacional Público. La Habana: Ed. Félix Varela.

Mirkine, B. (2008). Derecho Constitucional Internacional, traducción de Luis Legaz y Lacambra, Madrid: Ed. Reus, S.A.

Molina, R. (2010). Ensayo sobre el método para la interpretación y recepción de instituciones de derecho extranjero. Disponible enhttp://www.juridicas.unam.mx/publica/rev/indice.htm

. "Reglas sobre recepción de instituciones jurídicas extranjeras". Disponible en http://familiasjuridicascomparadas.blogspot.com

Pastor, J. A. (1992). Curso de Derecho Internacional Público y Organizaciones Internacionales, $4^{\text {a }}$ Edición. Madrid: Editorial TECNOS, S.A.

PÉREZ, L. (2011). Algunas consideraciones a debate sobre la ciencia jurídica y sus métodos. Revista Cubana de Derecho, 4(38), 23-50. Recuperado de http://vlex.com/source/revista-cubana-derecho-2615/issue_nbr/\%2338 
PINO, C. E. (2006). "La relación Derecho interno - Derecho internacional”. En Colectivo de Autores. Temas de Derecho Internacional Público, La Habana: Ed. Félix Varela,

Rabasa, O. (1933). El Derecho interno y el Derecho internacional. Del México actual, No. 4, Imprenta de la Secretaría de Relaciones Exteriores, México.

RICHARDS, O. (2011). La recepción de tratados internacionales en el ordenamiento jurídico cubano. Presupuestos teórico - jurídicos para su perfeccionamiento. Tesis presentada en opción al título de Máster en Derecho Constitucional y Administrativo. Universidad de La Habana, Cuba.

Rousseau, Ch. (1982). Derecho Internacional Público. Barcelona: Editorial Ariel.

SÁNCHEZ, O. (1999). La Constitución y los Tratados Internacionales. Un acercamiento a la interpretación judicial de la jerarquía de las normas y la aplicación de los Tratados en la legislación nacional, Supremo Tribunal de Justicia del Estado de Sinaloa, Cuadernos Jurídicos, 8. Culiacán, Sin.

Thomas, F. (2012). La aplicación de las normas del Derecho Internacional del Trabajo en el derecho interno. Revista Latinoamericana de Derecho Social Núm. 14, enero-junio, pp. 183-203.

Trejo, E. C., Arámbula, A. y Álvarez, M. (2006). Sistema de recepción de los Tratados Internacionales en el Derecho Mexicano. Servicios de Investigación y Análisis, Subdirección de Política Exterior. Disponible enhttp://www.diputados.gob.mx/cedia/sia/spe/SPE-ISS-07-06.pdf

Tunkin, G. (1988).Curso de Derecho internacional, Tomo I, $1^{\mathrm{a}}$ reimpresión. La Habana: Ed. Pueblo y Educación.

ZUPPI, A. L. (2010). Incorporación de tratados internacionales a la Constitución Nacional, sus efectos y consecuencias. Disponible en http://www.dpi.bioetica.org/docdpi/zuppi.htm 